\title{
Anti-migratory effect of rapamycin impairs allograft imaging by ${ }^{18} \mathbf{F}$-fluorodeoxyglucose-labeled splenocytes
}

\author{
HUKUI SUN ${ }^{1}$, DAYAN CHENG ${ }^{1}$, YUANYUAN MA ${ }^{1}$, HONG LIU $^{1}$, NING YANG $^{1}$, \\ CONG ZHANG $^{1}$, KAI WANG ${ }^{1}$, GUIHUA HOU ${ }^{2}$ and HUAQUAN WANG ${ }^{1}$ \\ ${ }^{1}$ Nuclear Medicine Department, Central Hospital of Zibo, Shandong University, Zibo, Shandong 255036; \\ ${ }^{2}$ Biomedical Isotope Research Center, School of Medicine, Shandong University, Jinan, Shandong 250012, P.R. China
}

Received August 23, 2015; Accepted May 10, 2016

DOI: $10.3892 / \mathrm{mmr} .2016 .5507$

\begin{abstract}
Tracking lymphocyte migration is an emerging strategy for non-invasive nuclear imaging of allografts; however, its clinical application remains to be fully demonstrated. In the present study, the feasibility of using rapamycin-treated $18 \mathrm{~F}$-fluorodeoxyglucose $\left({ }^{18} \mathrm{~F}\right.$-FDG)-labeled splenocytes for the in vivo imaging of allografts was evaluated. C57BL/6 skin was heterotopically transplanted onto non-obese diabetic/severe combined immunodeficient recipient mice. BALB/c ${ }^{18} \mathrm{~F}-\mathrm{FDG}$-labeled splenocytes with or without rapamycin pretreatment (designated as FR and FC cells, respectively) were transferred into recipient mice 30 days later. Imaging of radiolabeled cells in the skin grafts was conducted through in vivo dynamic whole-body phosphor-autoradiography and histological analysis. Notably, rapamycin impaired the migration of ${ }^{18} \mathrm{~F}$-FDG-labeled splenocytes to the graft. At all time points, the radioactivity of allografts (digital light units $/ \mathrm{mm}^{2}$ ) was significantly lower in the group that received FR cells, compared with the group that received FC cells $(\mathrm{P}<0.01)$. Furthermore, the peak allograft to native skin ratio was $1.29 \pm 0.02$ at $60 \mathrm{~min}$ for the FR group and 3.29 \pm 0.17 at 30 min for the FC group $(\mathrm{P}<0.001)$. In addition, the in vivo radioactivity of the allografts was observed to be correlated with the transferred cells, which were observed histologically $\left(r^{2}=0.887 ; \mathrm{P}<0.0001\right)$. Although ${ }^{18} \mathrm{~F}-\mathrm{FDG}$-labeled splenocytes migrated to the allograft, imaging of these cells may not be possible in the presence of rapamycin.
\end{abstract}

Correspondence to: Professor Huaiquan Wang, Nuclear Medicine Department, Central Hospital of Zibo, Shandong University, 54 Gongqingtuanxi Road, Zibo, Shandong 255036, P.R. China

E-mail: hqwangzb@aliyun.com

Abbreviations: ${ }^{18} \mathrm{~F}-\mathrm{FDG}, \quad{ }^{18} \mathrm{~F}-$ fluorodeoxyglucose; $\quad \mathrm{FC}$ cells, ${ }^{18}$ F-FDG-labeled splenocytes; FR cells, ${ }^{18} \mathrm{~F}-\mathrm{FDG}$-labeled rapamycin-treated splenocytes; mTOR, mammalian target of rapamycin; DLU, digital light units; AOR, allograft to opposite native skin ratio

Key words: ${ }^{18} \mathrm{~F}$-fluorodeoxyglucose-splenocytes, rapamycin, allograft, whole-body phosphor-autoradiography

\section{Introduction}

Organ transplantation is an effective treatment strategy for end-stage organ failure. Despite improvements in immunosuppressive strategies, allograft loss due to acute rejection remains a significant problem. Clinical detection of graft injury and rejection by repeated tissue biopsy is associated with certain risks $(1,2)$. Therefore, it is imperative to develop non-invasive approaches for in vivo imaging to facilitate the diagnosis and prognosis by evaluating the immune status and function of transplanted organs. Nuclear medical imaging is a reliable and highly sensitive technique allowing deep tissue penetration $(3,4)$. Currently, $18 \mathrm{~F}$-fluorodeoxyglucose $\left({ }^{18} \mathrm{~F}-\mathrm{FDG}\right)$ is the predominant radiolabel used to visualize the metabolic activity of immune cells. Previous studies have evaluated ${ }^{18} \mathrm{~F}$-FDG in the assessment of acute allograft rejection and the efficacy of immunosuppressive treatment $(5,6)$. Grabner et al (7) reported that ${ }^{18} \mathrm{~F}-\mathrm{FDG}$-labeled T lymphocytes accumulated in rat kidney allografts undergoing acute rejection.

As immunosuppressive treatments inhibit or prevent the proliferation and/or function of immune cells, including T cells, B cells and macrophages (8-10), the present study hypothesizes that the reliability of ${ }^{18} \mathrm{~F}$-FDG is impaired following organ transplantation. The aim of administering immunosuppressants is to impair the metabolic activity of effector cells, which results in decreased ${ }^{18} \mathrm{~F}$-FDG uptake. This was demonstrated in our previous research, which revealed that the immunosuppressant rapamycin significantly reduced ${ }^{18} \mathrm{~F}-\mathrm{FDG}$ uptake and prevented imaging of the graft (11). As an inhibitor of the intracellular kinase, mammalian target of rapamycin (mTOR), rapamycin is an immunosuppressive agent commonly administered to transplant recipients. Rapamycin exerts various effects on target cells, which include plasmacytoid dendritic cells (12), effector T cells (13), regulatory T cells $(14,15)$, B cells (9) and sensitive tumor cell lines (16). One consequence of mTOR inhibition is glycometabolism reduction $(17,18)$. In addition, mTOR inhibition blocks the proliferation, activation and trafficking of lymphocytes and inhibits the production of cytotoxic antibodies. Finlay et al (19) demonstrated that the phosphoinositide 3-kinase-mTOR signaling pathways determined the expression of key lymph node homing receptors (CD62 L and CCR7) and regulated lymphocyte trafficking. 
Therefore, whether ${ }^{18} \mathrm{~F}$-FDG and ${ }^{18} \mathrm{~F}$-FDG-labeled immune cells are suitable for use in the imaging of rapamycin-treated allografts remains to be elucidated.

In the present study, ${ }^{18} \mathrm{~F}-\mathrm{FDG}$-labeled splenocytes (with/without rapamycin treatment: FR and FC, respectively) were investigated for their potential application in allograft in vivo imaging. ${ }^{18} \mathrm{~F}$-FDG-labeled splenocytes were transferred into non-obese diabetic/severe combined immunodeficient (NOD/SCID) mice that had previously received skin allografts. Tracking of transferred cells was conducted using whole-body phosphor-autoradiography. The aim of this study was to evaluate whether ${ }^{18} \mathrm{~F}$-FDG-labeled splenocyte accumulation is affected by rapamycin treatment.

\section{Materials and methods}

Ethical approval. The animal protocol was reviewed and approved by the Institutional Animal Care and Use Committee at the School of Medicine, Shandong University (Jinan, China).

Animal model. Female NOD/LtSz-PrKdc scid (NOD/SCID; $\left.\mathrm{H}-2^{\mathrm{d}} ; \mathrm{n}=10\right)$ mice, BALB/c $\left(\mathrm{H}-2^{\mathrm{d}}\right)$ mice and C57BL/6 $\left(\mathrm{H}-2^{\mathrm{b}}\right.$; $\mathrm{n}=40$ ) mice aged $6-8$ weeks (weight, $18 \pm 2 \mathrm{~g}$ ) were bred and maintained under defined flora conditions in individually ventilated (HEPA-filtered air) sterile cages (19 days; humidity, 50-60\%). All mice were maintained under a 12-h light/dark cycle with access to standard mice chow and sterilized water ad libitum. Experiments were performed in accordance with national animal protection guidelines. Full-thickness skin grafts from donor C57BL/6 mice were harvested and transplanted onto the prepared graft beds on the right shoulders of recipient NOD/SCID mice (20). Surgeries were performed in a sterile environment under anesthesia with $0.6 \%$ pentobarbital sodium $(0.1 \mathrm{ml} / 10 \mathrm{~g}$ body weight $)$ by intraperitoneal (i.p.) injection. Buprenorphine (Reckitt Benckiser Pharmaceuticals, Richmond, Virginia, USA) was administered $(0.1 \mathrm{mg} / \mathrm{kg} / \mathrm{BW}$ i.p.) for 3 days after surgery to control wound pain. The wounds were then dressed. Bandages were removed 14 days later and the recipients with well-healed grafts were selected as the experimental subjects for imaging at 30 days post-transplantation ( $n=20$ per group).

Cell isolation and labeling. Splenocytes were isolated from BALB/c mice as previously described (21). The cells were cultured in cell culture plates in the constant temperature $\left(37^{\circ} \mathrm{C}\right)$ incubator with $10 \mathrm{U} / \mathrm{ml}$ recombinant interleukin 2 (rIL-2) or $10 \mathrm{U} / \mathrm{ml}$ rIL-2 and $100 \mathrm{nM}$ rapamycin (cat. no. M1768; AbMole Bioscience, Inc., Houston, TX, USA) for $24 \mathrm{~h}$. Cells were centrifuged and washed twice at $400 \mathrm{x} \mathrm{g}$ for 6 min at $4^{\circ} \mathrm{C}$ with fresh PBS and counted using a conventional Neubauer chamber. Splenocytes $\left(1 \times 10^{7}\right)$ were then incubated with $15 \mathrm{MBq}{ }^{18} \mathrm{~F}-\mathrm{FDG}$ (HTA Co., Ltd., Beijing, China) in $37^{\circ} \mathrm{C}$ potassium-enriched physiological saline containing $100 \mathrm{IU} / \mathrm{ml}$ insulin (Sigma-Aldrich, St. Louis, MO, USA) for $30 \mathrm{~min}$ (22). Splenocytes were collected by centrifugation at $400 \mathrm{x} g$ for 6 min at $4^{\circ} \mathrm{C}$, and radioactivity in the supernatant and pelleted cells was measured with a Wipe Test/Well $\gamma$-Counter (Capintec, Inc., Ramsey, NJ, USA). Labeling efficiency was defined as the ratio of radioactivity of cells to overall radioactivity. To analyze labeling stability, ${ }^{18} \mathrm{~F}$-FDG-labeled splenocytes $\left(5 \times 10^{6}\right)$ were incubated in mouse blood plasma (total volume, $400 \mu$ l; Shanghai Fanke Biotechnology Co., Ltd., Shanghai, China) for $5,10,30,60$ and $90 \mathrm{~min}$. The ratios of radioactivity of cells to overall radioactivity (the labeling stability) were calculated. Cells were divided into two groups: ${ }^{18} \mathrm{~F}-\mathrm{FDG}$-labeled control (FC) cells and ${ }^{18} \mathrm{~F}-\mathrm{FDG}$-labeled rapamycin-treated (FR) cells.

Image acquisition: Dynamic whole-body phosphor-autoradiography. Recipient mice were injected with $1 \times 10^{7} \mathrm{FC}$ or FR cells via the tail vein. The imaging was performed under isoflurane (Sigma-Aldrich) inhalation anesthesia (induction, $3 \%$; maintenance, $1.5 \%$ ). Anesthetized mice were placed on the storage phosphor screen plate with their backs to the plate, in subdued light. The plate was exposed for $10 \mathrm{~min}$. At cessation of exposure, the plate was immediately covered with an opaque plastic sheet, then transferred to the Cyclone Plusscanner (PerkinElmer Life Sciences, Waltham, MA, USA). Dynamic in vivo whole-body phosphor-autoradiography was performed at 30, 60 and 90 min following injection of radiolabeled cells. Semi-quantitative analysis was performed by manually drawing rectangular regions of interest $(n=5)$ within the graft at each time point. Digital light units (DLU) $/ \mathrm{mm}^{2}$ were obtained using OptiQuant ${ }^{\mathrm{TM}}$ image analysis software 5.0 (PerkinElmer Life Sciences).

Histology. Portions of skin grafts were harvested, and stained with hematoxylin and eosin for histologic evaluation according to a previous study (20). The slides were visualized with an inverted microscope (DMIRB; Leica Microsystems GmbH, Wetzlar, Germany) at x10 and x20 magnifications. Infiltrating splenocytes were quantified in five x20 fields.

Statistical analysis. Data are presented as means \pm SD (standard deviation). Statistical analysis was performed using the paired $t$-test by GraphPad Prism version 5 software (GraphPad Software, Inc., La Jolla, CA, USA). P<0.05 was considered to indicate a statistically significant difference. The non-parametric Spearman's rho test was used to assess the association between the accumulation of labeled splenocytes, as measured by radioactivity, and the number of splenocytes, which was assessed histologically.

\section{Results}

Mouse model and radiolabeling of splenocytes. A representative C57BL/6 skin graft on the right shoulder of a NOD/SCID mouse is presented in Fig. 1A. Although rapamycin reduces the glycometabolism function of host immune cells during the rejection response, no significant difference was identified in labeling efficiency between the FC and FR cells (Fig. 1B). In the FC cells, labeling stability was evaluated and the percentage of labeled cells slowly decreased in vitro over time, as retention of ${ }^{18} \mathrm{~F}-\mathrm{FDG}$ in the cells declined from $92.4 \pm 1.7 \%$ at $5 \mathrm{~min}$ to $73.2 \pm 8.1 \%$ at $30 \mathrm{~min}, 62.6 \pm 2.0 \%$ at $60 \mathrm{~min}$ and $57.7 \pm 6.2 \%$ at $90 \mathrm{~min}$ (Fig. $1 \mathrm{C}$ ).

In vivo imaging. Whole-body phosphor-autoradiography of allografts revealed significantly reduced radioactivity $\left(\mathrm{DLU} / \mathrm{mm}^{2}\right)$ in the transplanted skin area (allograft) of mice that received FR cells compared with those that received FC 
A

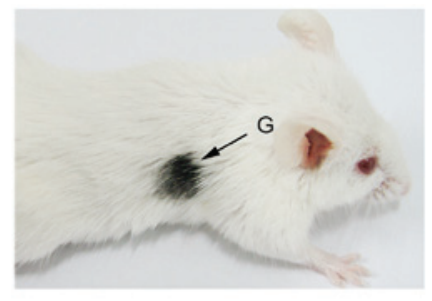

B

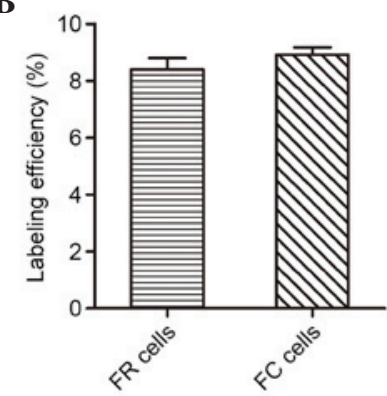

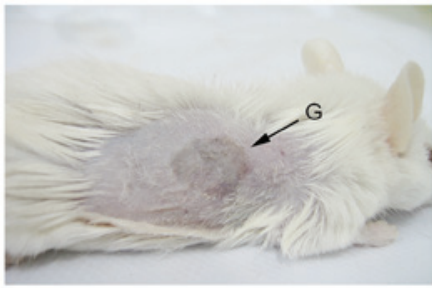

C

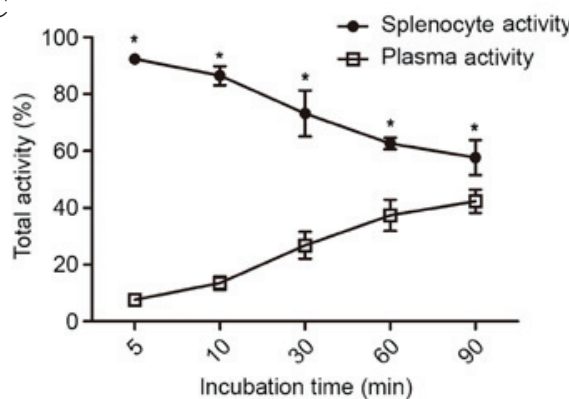

Figure 1. Mouse model and radiolabeling of splenocytes. (A) Skin from a C57BL/6 mouse was transplanted onto the right shoulder of a non-obese diabetic/severe combined immunodeficient mouse. The grafted skin grew black hair. Shaving of the area revealed that the wound had healed well. (B) FR and FC cells $(n=3)$ were labeled with ${ }^{18}$ F-FDG $\left(1 \times 10^{7}\right.$ cells; $\left.15 \mathrm{MBq}\right)$. Note, as the half-life of ${ }^{18} \mathrm{~F}$-FDG is short ( 110 min) and the ${ }^{18} \mathrm{~F}-\mathrm{FDG}$ membrane transportation, an overdose of ${ }^{18} \mathrm{~F}$-FDG was used. No difference was observed in the labeling efficiency. (C) Labeling stability was analyzed at 5,10 , 30,60 and $90 \mathrm{~min}$. Retention of ${ }^{18} \mathrm{~F}-\mathrm{FDG}$ in cells slowly decreased from $92.4 \pm 1.7$ at 5 min to $57.7 \pm 6.2 \%$ at $90 \mathrm{~min}\left(\mathrm{n}=5\right.$ ). ${ }^{*} \mathrm{P}<0.05 \mathrm{vs}$. plasma activity. G, graft; FDG, fluorodeoxyglucose; FR cells, ${ }^{18} \mathrm{~F}$-FDG-labeled rapamycin-treated splenocytes; FC cells, ${ }^{18} \mathrm{~F}-\mathrm{FDG}-\mathrm{labeled}$ splenocytes.

cells, at 30,60 and $90 \mathrm{~min}$ (Fig. 2A). The opposite native skin in all mice exhibited consistently low radioactivity (Fig. 2B). The peak of allograft to opposite native skin ratio (AOR) was significantly lower in the FR cell group $(1.29 \pm 0.02$ at $60 \mathrm{~min})$ compared with the FC cell group $(3.29 \pm 0.17$ at $30 \mathrm{~min} ; \mathrm{P}<0.001)$ (Fig. 2C). Whole-body phosphor-autoradiography revealed a clearly elevated radioactive signal in the allograft area $30 \mathrm{~min}$ following injection, which indicated a significant accumulation of FC cells in skin allografts (Fig. 3A). High-uptake organs included the brain, heart and spleen. This may be due to lymphocytes homing to the spleen and non-specific uptake of free ${ }^{18} \mathrm{~F}-\mathrm{FDG}$ dissociated from FC cells. However, images of FR cells did not enable graft visualization at any time point (Fig. 3B). These results confirmed that the migration of FR cells to graft areas was notably impaired.

Histology. Representative images of allograft sections were stained with hematoxylin and eosin to estimate lymphocytic infiltration, and are presented in Fig. 4A. As exhibited in Fig. 4B, significant infiltration of lymphocytes was absent in the grafts of mice injected with FR cells $(\mathrm{P}<0.001)$. The number of splenocytes per field of view was then correlated with radioactivity of the graft (Fig. 4C), and revealed to be significantly correlated $\left(\mathrm{r}^{2}=0.887 ; \mathrm{P}<0.0001\right)$.

\section{Discussion}

Currently, the lack of effective parameters to assess allograft function and rejection status limits the success of treatment. Lymphocyte migration, a crucial element during the development of the acute alloimmuneresponse, mediates the immune response during acute allograft rejection; therefore, lymphocytes present as attractive biomarkers and targets for graft imaging. Thus, the tracing of lymphocyte trafficking has been evaluated for allograft monitoring and even prediction of allograft survival $(23,24)$. However, the use of immunosuppressants following clinical organ transplantation severely impairs the proliferation and trafficking of lymphocytes, and it therefore remains to be elucidated whether imaging of lymphocytes has clinical applications. In the present study, C57BL/6 skin was transplanted onto NOD/SCID recipient mice, which then received FC or FR BABL/c splenocytes 30 days later. NOD/SCID recipient mice, used to reduce the severity of the immunologically mediated surgical injury, are deficient in $\mathrm{T}$ and B lymphocytes and have impaired natural killer cells and complement function. The fully mismatched allografts do not undergo rejection; therefore, the trafficking of transferred cells could be monitored more accurately (25).

The results of the present study revealed that rapamycin had minimal impact on the uptake of ${ }^{18} \mathrm{~F}-\mathrm{FDG}$ by naive lymphocytes. No significant difference in labeling efficiency and stability was identified between FC and FR cells. FC cell accumulation was observed in the allograft area with high radioactivity and AORs at all time points; however, FR cell accumulation in allografts was never clearly imaged. Histological analysis was performed and confirmed reduced FR cell accumulation in allografts. The present study employs molecular imaging to extend the results of a previous study in which ${ }^{18} \mathrm{~F}-\mathrm{FDG}$ was determined to be unsuitable as a rapamycin-treated graft biotracer (11). In the present study, the accumulation of FR cells in the allograft was barely visible when compared with FC cells. Furthermore, a significant correlation was observed between allograft radioactivity and splenocyte infiltration, which was determined by histology.

There are several limitations of the present study. The rapamycin dose was selected according to a previous study, which revealed it to be effective at controlling lymphocyte trafficking (26). This was confirmed by the results of the 
A

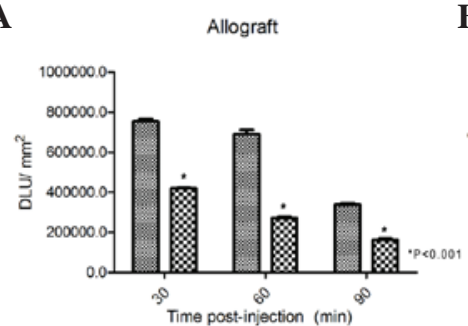

B

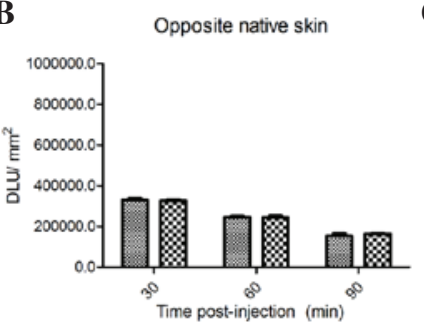

C

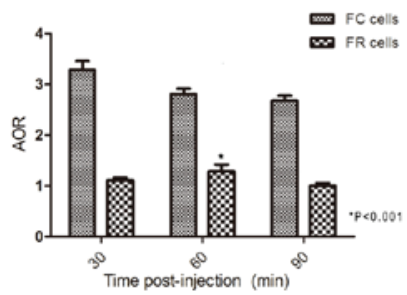

Figure 2. Dynamic radioactivity of allograft and opposite native skin are presented as DLU/mm² \pm standard error ( $\mathrm{n}=5$ ) using the cyclone plus storage phosphor System at various time points following tail vein injection of FR or FC cells. (A) The allografts of mice that received FR cells were less radioactive than those that received FC cells. "P<0.001, vs. FC cells. (B) The opposite native skin in all mice exhibited consistently low radioactivity. (C) The peak AOR was significantly reduced in the FR cell group compared with that in FC cell group. ${ }^{*} \mathrm{P}<0.001$, for the AOR value of FR cells at 60 min vs. the AOR value of FC cells at $30 \mathrm{~min}$. FDG, fluorodeoxyglucose; FC cells, ${ }^{18} \mathrm{~F}$-FDG-labeled splenocytes; FR cells, ${ }^{18} \mathrm{~F}$-FDG-labeled rapamycin-treated splenocytes; DLU, digital light units; AOR, allograft to opposite native skin ratio.

A

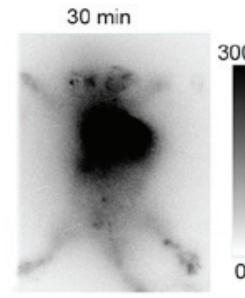

B

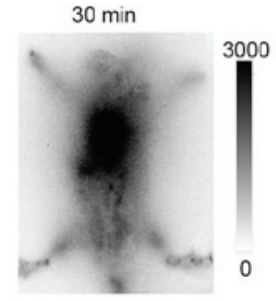

$60 \mathrm{~min}$

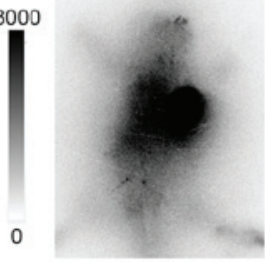

$60 \mathrm{~min}$
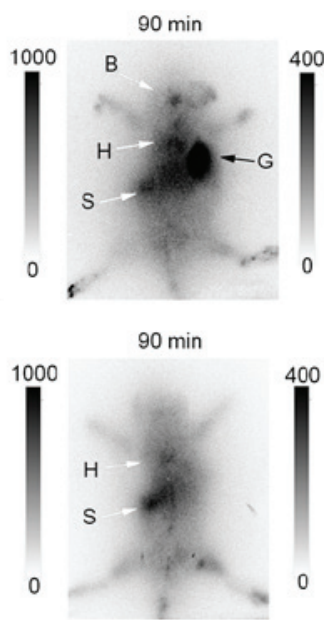

Figure 3. Representative images of dynamic whole-body phosphor-autoradiography of mice injected with (A) ${ }^{18}$ F-FDG-labeled splenocytes and (B) ${ }^{18} \mathrm{~F}$-FDG-labeled rapamycin-treated splenocytes. Images were acquired at 30, 60 and 90 min following injection of ${ }^{18} \mathrm{~F}-\mathrm{FDG}-\mathrm{labeled}$ cells $\left(1 \times 10^{7}\right)$. Accumulation of ${ }^{18} \mathrm{~F}$-FDG-labeled cells was observed in the graft (G), brain (B), heart (H) and spleen (S). FDG, fluorodeoxyglucose.

A

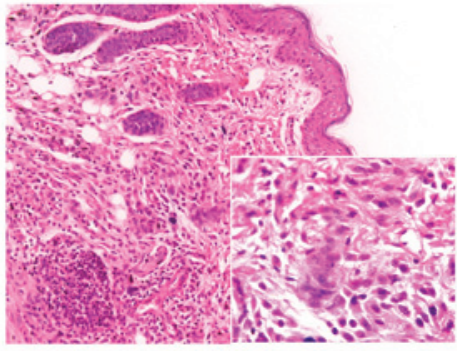

B

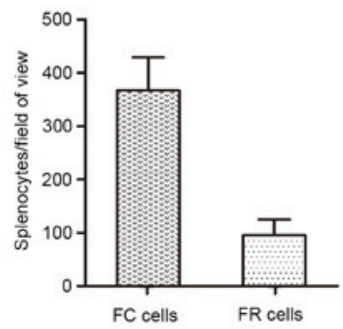

b

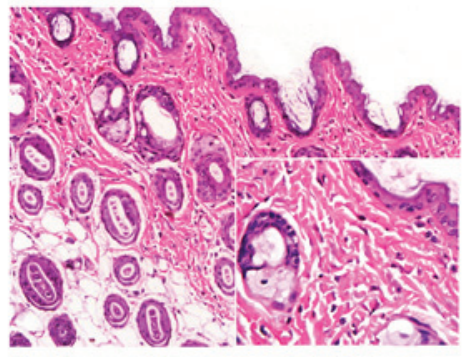

C

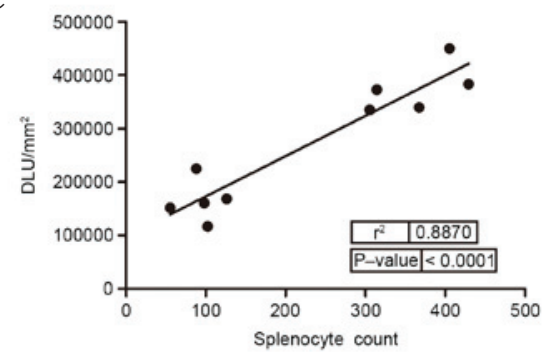

Figure 4. (A) Representative images of hematoxylin and eosin-stained skin grafts of mice injected with (a) FC or (b) FR cells were captured at x10 magnification. A x20 magnification image is presented in the boxed regions. (B) Quantification of infiltrated splenocytes at x20 magnification revealed significantly increased accumulation in grafts of mice injected with FC cells compared with those injected with FR cells $(\mathrm{P}<0.001)$. (C) Accumulation of labeled splenocytes and radioactivity in grafts were significantly correlated $\left(\mathrm{r}^{2}=0.887\right.$; $\left.\mathrm{P}<0.0001\right)$. FDG, fluorodeoxyglucose; FC cells, ${ }^{18} \mathrm{~F}-\mathrm{FDG}-\mathrm{labeled}$ splenocytes; FR cells, 18F-FDG-labeled rapamycin-treated splenocytes; DLU, digital light units. 
present study; however, no alternative doses were evaluated. In addition, to avoid interference by the recipient's immune response, labeled BALB/c lymphocytes were transferred into NOD/SCID, rather than BALB/c, recipients. This may not be reflective of the physiological situation.

Despite increasing knowledge of the rejection process and tolerance induction, elements of these processes have not been extensively investigated as imaging targets. In acute rejection, the non-specific accumulation of ${ }^{18} \mathrm{~F}$-FDG-labeled immune cells at sites of inflammation following surgery impedes the accurate assessment of the immune response $(27,28)$. Clinically, immunosuppressive treatments have been shown to inhibit immune cell migration, which rendered postoperative detection of grafts impossible (29). Thus, the use of labeled lymphocytes in in vivo imaging remains controversial. The results of the present study suggest that splenocyte trafficking was impaired by the mTOR inhibitor, rapamycin and is therefore not a suitable method for monitoring patients receiving this particular immunosuppressant. Alternative imaging strategies are required, which will enable determination of graft function and immune status in the presence of immunosuppressive therapy.

\section{Acknowledgements}

The present study was supported by a grant from the National Natural Science Foundation of China (grant no. 81371601).

\section{References}

1. Baraldi-Junkins C, Levin HR, Kasper EK, Rayburn BK, Herskowitz A and Baughman KL: Complications of endomyocardial biopsy in heart transplant patients. J Heart Lung Tranplant 12: 63-67, 1993.

2. Mueller TF, Reeve J, Jhangri GS, Mengel M, Jacaj Z, Cairo L, Obeidat M, Todd G, Moore R, Famulski KS, et al: The transcriptome of the implant biopsy identifies donor kidneys at increased risk of delayed graft function. Am J Transplant 8: 78-85, 2008.

3. Virostko J, Henske J, Vinet L, Lamprianou S, Dai C, Radhika A, Baldwin RM, Ansari MS, Hefti F, Skovronsky D, et al Multimodal image coregistration and inducible selective cell ablation to evaluate imaging ligands. Proc Natl Acad Sci USA 108: 20719-20724, 2011.

4. Signore A, Mather SJ, Piaggio G, Malviya G and Dierckx RA: Molecular imaging of inflammation/infection: Nuclear medicine and optical imaging agents and methods. Chem Rev 110: 3112-3145, 2010

5. Tsuji AB, Morita M, Li XK, Sogawa C, Sudo H, Sugyo A Fujino M, Sugioka A, Koizumi M and Saga T: 18F-FDG PET for semiquantitative evaluation of acute allograft rejection and immunosuppressive therapy efficacy in rat models of liver transplantation. J Nucl Med 50: 827-830, 2009.

6. Reuter S, Schnöckel U, Edemir B, Schröter R, Kentrup D, Pavenstädt H, Schober O, Schlatter E, Gabriëls G and Schäfers M: Potential of noninvasive serial assessment of acute renal allograft rejection by $18 \mathrm{~F}-\mathrm{FDG}$ PET to monitor treatment efficiency. J Nucl Med 51: 1644-1652, 2010.

7. Grabner A, Kentrup D, Edemir B, Sirin Y, Pavenstädt H, Schlatter E, Schober O, Schäfers M, Schnöckel U and Reuter S: PET with F-18-FDG-labeled T lymphocytes for diagnosis of acute rat renal allograft rejection. J Nucl Med 54: 1147-1153, 2013.

8. Kimura T, Hasegawa T, Nakai H, Azuma T, Usui N, Sasaki T and Okada A: FTY720 reduces T-cell recruitment into murine intestinal allograft and prevents activation of graft-infiltrating cells. Transplantation 75: 1469-1474, 2003.

9. Heidt S, Roelen DL, Eijsink C, van Kooten C, Claas FH and Mulder A: Effects of immunosuppressive drugs on purified human B cells: Evidence supporting the use of MMF and rapamycin. Transplantation 86: 1292-1300, 2008.
10. Brown FG, Nikolic-Paterson DJ, Metz C, Bucala R, Atkins RC and Lan HY: Up-regulation of macrophage migration inhibitory factor in acute renal allograft rejection in the rat. Clin Exp Immunol 118: 329-336, 1999.

11. Sun H, Yang G, Liang T, Zhang C, Song J, Han J and Hou G: Non-invasive imaging of allogeneic transplanted skin graft by 131I-anti-TLR5 mAb. J Cell Mol Med 18: 2437-2444, 2014.

12. Cao W, Manicassamy S, Tang H, Kasturi SP, Pirani A, Murthy N and Pulendran B: Toll-like receptor-mediated induction of type I interferon in plasmacytoid dendritic cells requires the rapamycin-sensitive PI (3)K-mTOR-p70S6K pathway. Nat Immunol 9: 1157-1164, 2008

13. Strauss L, Czystowska M, Szajnik M, Mandapathil M and Whiteside TL: Differential responses of human regulatory $\mathrm{T}$ cells (Treg) and effector T cells to rapamycin. PLoS One 4: e5994, 2009.

14. Sauer S, Bruno L, Hertweck A, Finlay D, Leleu M, Spivakov M, Knight ZA, Cobb BS, Cantrell D, O'Connor E, et al: T cell receptor signaling controls Foxp3 expression via PI3K, Akt, and mTOR. Proc Natl Acad Sci USA 105: 7797-7802, 2008.

15. Battaglia M, Stabilini A and Roncarolo MG: Rapamycin selectively expands CD4+CD25+FoxP3+ regulatory T cells. Blood 105: 4743-4748, 2005.

16. Hidalgo $\mathrm{M}$ and Rowinsky EK: The rapamycin-sensitive signal transduction pathway as a target for cancer therapy. Oncogene 19: 6680-6686, 2000.

17. Wullschleger S, Loewith R and Hall MN: TOR signaling in growth and metabolism. Cell 124: 471-484, 2006.

18. Teutonico A, Schena PF and Di Paolo S: Glucose metabolism in renal transplant recipients: Effect of calcineurin inhibitor withdrawal and conversion to sirolimus. J Am Soc Nephrol 16: 3128-3135, 2005.

19. Finlay D and Cantrell D: Phosphoinositide 3-kinase and the mammalian target of rapamycin pathways control $\mathrm{T}$ cell migration. Ann N Y Acad Sci 1183: 149-157, 2010.

20. Hou G, Valujskikh A, Bayer J, Stavitsky AB, Metz C and Heeger PS: In vivo blockade of macrophage migration inhibitory factor prevents skin graft destruction after indirect allorecognition. Transplantation 72: 1890-1897, 2001

21. Fantini MC, Dominitzki S, Rizzo A, Neurath MF and Becker C: In vitro generation of CD4+CD25+ regulatory cells from murine naive T cells. Nat Protoc 2: 1789-1794, 2007.

22. Meier R, Piert M, Piontek G, Rudelius M, Oostendorp RA, Senekowitsch-Schmidtke R, Henning TD, Wels WS, Uherek C, Rummeny EJ and Daldrup-Link HE: Tracking of [18F] FDG-labeled natural killer cells to HER2/neu-positive tumors. Nucl Med Biol 35: 579-588, 2008.

23. Butler KS, Lovato DM, Adolphi NL, Belfon R, Fegan DL, Monson TC, Hathaway HJ, Huber DL, Tessier TE, Bryant HC, et al: Development of antibody-tagged nanoparticles for detection of transplant rejection using biomagnetic sensors. Cell Transplant 22: 1943-1954, 2013.

24. Tanaka M, Swijnenburg RJ, Gunawan F, Cao YA, Yang Y, Caffarelli AD, de Bruin JL, Contag $\mathrm{CH}$ and Robbins RC: In vivo visualization of cardiac allograft rejection and trafficking passenger leukocytes using bioluminescence imaging. Circulation 112 (9 Suppl): I105-I110, 2005.

25. Greiner DL, Shultz LD, Yates J, Appel MC, Perdrizet G, Hesselton RM, Schweitzer I, Beamer WG, Shultz KL, Pelsue SC, et al: Improved engraftment of human spleen cells in NOD/LtSz-scid/scid mice as compared with C.B-17-scid/scid mice. Am J Pathol 146: 888-902, 1995.

26. Valmori D, Tosello V, Souleimanian NE, Godefroy E, Scotto L, Wang Y and Ayyoub M: Rapamycin-mediated enrichment of T cells with regulatory activity in stimulated CD4+ T cell cultures is not due to the selective expansion of naturally occurring regulatory $\mathrm{T}$ cells but to the induction of regulatory functions in conventional CD4+ T cells. J Immunol 177: 944-949, 2006.

27. Ishimori T, Saga T, Mamede M, Kobayashi H, Higashi T, Nakamoto Y, Sato N and Konishi J: Increased (18)F-FDG uptake in a model of inflammation: Concanavalin A-mediated lymphocyte activation. J Nucl Med 43: 658-663, 2002.

28. Pellegrino D, Bonab AA, Dragotakes SC, Pitman JT, Mariani G and Carter EA: Inflammation and infection: Imaging properties of 18F-FDG-labeled white blood cells versus 18 F-FDG. J Nucl Med 46: 1522-1530, 2005.

29. Chen DL, Wang X, Yamamoto S, Carpenter D, Engle JT, Li W, Lin X, Kreisel D, Krupnick AS, Huang HJ and Gelman AE: Increased $\mathrm{T}$ cell glucose uptake reflects acute rejection in lung grafts. Am J Transplant 13: 2540-2549, 2013. 